\title{
Interactive comment on "Applicability of
} Landsat 8 Thermal Infrared Sensor to Identify Submarine Groundwater Discharge Springs in the Mediterranean Sea Basin" by Sònia Jou-Claus \section{et al.}

\section{Sònia Jou-Claus et al.}

soniajouclaus@gmail.com

Received and published: 31 March 2021

Dear Prof. Marnik Vanclooster,

Thank you very much for your letter with the Editor's and Reviewers' thorough comments on our manuscript. We sincerely appreciate the effort devoted by the two Reviewers on revising the manuscript and we are pleased to see that our work might be considered worthy for publication. We have now prepared a revised version of the manuscript and a letter with a detailed point-by-point response to the comments of re- 
viewers. Please find enclosed our responses and actions undertaken in response to each comment. We have also added the modified text that would appear in the revised version of the manuscript.

Sincerely,

Sònia Jou-Claus et al.

\section{Reviewer\#1}

The authors investigate the detection potential of submarine groundwater discharge (SGD) using thermal infrared (TIR) images acquired by the Landsat 8 satellite. Their approach's novelty is that they test the detection capability by looking at $50+$ known SGD sites along the Mediterranean coastline. For each site, they checked whether or not the SGD was detectable through image interpretation, and they describe a list of factors that could be underlying any failure to detect the SGD. As such, the authors claim that they "analyze the appropriateness of satellite TIR-RS data for SGD research in a statistically robust manner."

The topic of this paper is promising and of important interest. However, the work that has been conducted is exploratory and present weaknesses that would need to be addressed before being ready for publication. I highlight here the most critical points of concern and have added comments in the manuscript (Supplement PDF) that would also have to be fully considered.

Thank you for considering that the topic of this paper is promising and important and also for the extensive review of the manuscript. We answer and address all of your comments below.

Comment 1: I have no experience working with TIR products. Based on the text provided, it is difficult to judge whether the image processing that has been applied is robust. The references provided to back up do not seem to align with the application. They are also surprisingly old, while one would expect that robust algorithms would 
have been developed more recently?

Answer: We thanks to the reviewer for his observation. This methodology was initially proposed by Chander et al. (2009), which provides a summary of the equations and rescaling factors for convert the digital numbers (DN) to sensor spectral radiance, TopOf-Atmosphere (TOA) radiance and sensor brightness temperature. Despite the fact that this initial methodology was proposed some time ago, it is the one used to process Landsat 8 images. For example, Wilson \& Rocha (2012) used the same approach to sucessfully detect plumes of colder water associated with SGD in close proximity to the shoreline of Ireland. Mallast et al., (2014) used the same approach, applied to the Dead Sea, to infer a temporal variation of SGD using the size variations of long-term thermal anomalies. To our knowledge, there are not more recent studies proposing a new algorithm for processing this type of satellite images. All this bibliography has been cited in the manuscript.

Action: No action will be done.

Comment 2: It would also be useful to present the accuracy and expected range of error on the final Sea surface temperature product.

Answer: Many thanks for the appreciation. This data was included in the Methodology the end of section 2.3 (Deriving SST values from Landsat 8 TIRS data). As mentioned in the manuscript the resulting atmospherically-corrected SST data has an error of less than $1.3^{\circ} \mathrm{K}$ for the temperature range of $270-330^{\circ} \mathrm{K}$ (Wloczyk et al., 2006).

Action: No action will be done.

Comment 3: Another concern is about the atmospheric correction. The Landsat TIR products are initially developed for terrestrial applications. Was the atmospheric correction algorithm applied suited for such an aquatic study?

Answer: Thank you for your comment. Yes, the algorithm applied can be also suited for such an aquatic study. In order to atmospherically correct images at sensor spectral 
radiance in water studies, it is necessary to transform them into a surface radiance of an ideal "black body" considering the 1) point specific up-and down- welling radiance,

2) transmission values and 3) the emissivity of the earth surface, in that case water emissivity, which in band 10 was 0.9904 (Wen-Yao et al., 1987).

Action: Following the reviewer comment, we will add this information in the new version of the manuscript as follows (L188).

The next step was an atmospheric correction to remove the atmospheric component of the recorded thermal signal which strongly depends on atmospheric conditions (aerosol content, humidity, temperature etc.) at a specific recording time and place. To atmospherically correct images at sensor spectral radiance, it was necessary to transform them into surface radiance of an ideal 'black body', considering the scenespecific up- and down- welling radiance and transmission values and the emissivity of the water surface, according to Equation (2) (Barsi et al., 2003). A web-based atmospheric correction tool developed by Barsi et al. (2003) based on MODTRAN was used to obtain values for atmospheric transmissivity and the upwelling and downwelling radiances of the atmosphere. The applied value for water emissivity in band 10 was 0.9904 (Wen-Yao et al., 1987). Finally, to obtain the sea surface temperature (SST), the corrected radiances were introduced into Equation (3).

Comment 4: The selection criteria for the SGD should be further detailed, and the specificities of each spring/cluster of springs described. A table could be an efficient way to do so. So far, statistics (average or range) are given for the ensemble of springs, which is not sufficient to understand the diversity of study sites. Such characterization would also be useful to help interpret the findings; see comment below in that regard.

Answer: Thank you for this suggestion. The selection criterion was to include all documented springs in English peer-reviewed journals. The hydrogeological data presented for each spring (depth of the discharge, distance to the shoreline, flow rate etc.) corresponds to the data available in each publication, which was not homogeneous. We will 
specify this in section 2.1 line 147.

Action: we will add a new table in SM in the revised version of the manuscript summarizing all the information available for each spring and they particularities. This table will include the available information in the literature of the springs characteristics: Flow rate, discharge depth, distance to the shoreline, type of karstic system and the source of the available information.

Interactive comment

Comment 5: The success or failure in detecting an SGD point with TIR should be discussed in light of the given sites characteristics. It's partly done, but not consistently. A more quantitative analysis would greatly help and add value to this work. On the other hand, the study conducted so far is not robust enough to state that you "analyze the appropriateness of satellite TIR-RS data for SGD research in a statistically robust manner."

Answer: We agree with the reviewer that it would be great to perform a quantitative analysis of the work carried out. However, as indicated in the previous answer, the information available in the published scientific literature for each spring, such as the discharge depth, distance to the shoreline, flow rate etc. is limited and it is not enough to perform a quantitative analysis or a statistical study. However, we think that the data present is enough to quantify the success of the technique since we are observing the majority of the published SGD springs along the Mediterranean coast. Likewise, we think that the qualitative information we present according to the data available, is very significant to apply this technique in a standard way to study SGD springs in other areas.

Action: Following the reviewer comment, in order to improve discussion about the success or failure in detecting SGD springs of the given sites, we will add, in the supplementary material of the reviewed version of the manuscript, a box plot (with the available hydrogeologic information) of the success or failure in the identification of the springs considering the limitation factors that could condition the identification of the 
springs.

Following the comment of the reviewer we will rephrase this state "analyze the appropriateness of satellite TIR-RS data for SGD research in a statistically robust manner" in a new version of the manuscript. The text will read as (L109 - L112):

To our best knowledge, there is no study that thoroughly compares known SGD locations with indications of satellite-data derived thermal anomaly over larger spatial scales to analyze the appropriateness of satellite TIR-RS data for SGD research.

Comment 6: A major concern I have with this paper is that many limitations are presented as a result, while most are assumptions that this work has not allowed verifying. An example of this is the anthropogenic effect. While these assumptions can either be presented as a problem statement in the introduction or used to discuss your results, they should not be presented as results per se.

Answer: Thank you very much for your comment. In this study we analyzed SGD springs previously described in the literature and thus we know the area where the submarine groundwater discharge occurs. However, a surprisingly high proportion of springs could not be identified, even though the satellite remote sensing TIR technique had been successfully applied in other areas of the planet. Our results were that, out of the total of 54 SGD studied springs, only 23 springs were identified, representing a $44.4 \%$ success rate of the technique. For this reason, we hypothesize and discuss the main factors that may condition the identification of the springs using satellite TIR images. We think that this discussion could be helpful for future studies for detect SGD springs worldwide in zones without hydrogeological information.

Action: To clarify the message and the aim of the article we will modify have the objectives of the new version of the manuscript as follows (L128 - L132).

To validate the temporal effectiveness of this technique, Landsat-8 images from 2017 and 2018 on the coasts of the Mediterranean Sea basin were used to locate SGD 
springs previously described in the scientific literature, showing in which period of the year these SGD springs are observable with satellite. In addition, we will hypostatize and discuss those factors that may condition the identification of SGD springs in order that future studies can take them into account in the use of satellite remote sensing TIR technique.

Comment 7: Following up on the previous comment, I do not think that this study offers any conceptual framework, as is stated. This study is an exploratory analysis of the capabilities to detect SDG in karstic systems with TIR. That alone could be enough for a paper once it is reworked.

Answer: Thank you your comment and we agree with your consideration. Following up on over previous comment, the aim of the article is to know the success or failure in identifying SGD springs previously reported in the scientific literature. But as mentioned before, the results have shown that the identifications only be success in the $44.4 \%$ of the studied springs. To improve the presented research and to facilitate the use of this technique in future works we hypothesize and discuss which are the reasons that may condition the identification of SGD springs.

Action: Following the reviewer comment we will change the name of the section form "conceptual framework" to "Factors for considering in the identification of SGD springs" in the new version of the manuscript.

Comment 8: Overall, the text would benefit from rewriting in a more distilled and synthetic message. So far, the paragraphs are often long and convoluted.

Answer: Thanks for the comment.

Action: We will revise it to rewrite it in a more distilled and synthetic writing in a reviewed version of the manuscript.

Technical corrections: 
Action: The change will be made according to the reviewer suggestion.

L117 Your study set up did not allow to draw conclusions for worldwide applications

Answer: Thanks for the comment. We have decided to keep this sentence because, although we know that this approach cannot be applied in all coastal geological environments, satellite TIR imagery can be obtained worldwide and used to investigate potential SGD springs or zones of influence with thermal or other optical imaging. Examples of this application outside the Mediterranean sea could be Hawaii (Johnson et al., 2008) or Java (Oehler et al., 2018).

Action: No action has been done.

$\mathrm{Pg}$ 4, L127 you mean freshwater resources?

Answer: Yes, thank you for the comment.

Action: We will correct the text in the new version of the manuscript as follows (L126 - L127): ... locally important, strongly influencing marine ecosystems and serving as a freshwater resource for the population (Rodellas et al., 2015; Moosdorf \& Oehler, 2017).

L131 can you really test that given that you focus on karstic envi?

Answer: Thank you for your comment. We agree with the reviewer comment and we could not test under what hydrogeological conditions these SGD springs are observable with satellite because we only focus on springs that are commonly developed in a specific geological context such as karstic environments.

Action: We will modify the objective in the new version of the manuscript as follows (L128-L132): To validate the temporal effectiveness of this technique, Landsat-8 images from 2017 and 2018 on the coasts of the Mediterranean Sea basin were used to locate SGD springs previously described in the scientific literature, showing in which period of the year these SGD springs are observable with satellite. In addition, we 
will hypostatize and discuss those factors that may condition the identification of SGD springs in order that future studies can take them into account in the use of satellite remote sensing TIR technique.

L148 What were the selection criteria? Can you give some information on how representative this selection of SGDs is for the Mediterranean basin?

Answer: Thank you for the suggestion. As mentioned before, in this study we included all springs in the Mediterranean reported in the English scientific literature. For this reason, we think that this information is representative of the Mediterranean basin.

Action: Following the reviewer comment and to clarify the importance of the study presented we will modify the text as follows (L148- L156):

The Mediterranean basin has been selected for this study because it is one of the areas of the world where numerous SGD studies have been carried out and where dozens of coastal springs have been described since ancient times in countries such as Spain, France, Italy, Croatia, Greece, Turkey, Syria, Lebanon and Libya (Figure 1). In this study, we focus on a set of 54 springs mentioned in the scientific literature published in English (e.g., Bakalowicz, 2018; Basterretxea et al., 2010; Fleury et al., 2007; 150 Mejías et al., 2012) where groundwater discharge is known to occur and there is a description of the hydrogeological context of each spring (Supplementary Material 1). The number of springs included in the study represents at least $88 \%$ of the submarine karst springs described in the literature in the Mediterranean basin.

Pg5, L167 what wavelength does it correspond to?

Answer: The wavelength corresponds to a wavelength of 10.6-11.2 $\mu \mathrm{m}$.

Action: The new version of manuscript now reads (L167 - L169):

Only band $10(10.6-11.2 \mu \mathrm{m})$ has been used to study temperature differences in water to detect SGD sites, because data collected in band $11(11.5-12.5 \mu \mathrm{m})$ of the TIRS has some large calibration uncertainties (U.S. Geological Survey, 2014b). 
L168 I thought there was only two bands in TIRS? Why do they name them 10 and 11 ? Please be more explicit with new terms used.

Answer: Landsat 8 Operational Landsat Imager (OLI) and Thermal Infrared Sensor (TIRS) have 11 bands. The bands from 1 to 9 consist of spectral bands and bands 10 (TIRS 1) and 11 (TIRS 2) are thermal bands.

Action: Following the reviewer comment we will modify the text as follows (L167-L169):

To carry out this study, only the thermal band 10 TIRS $1(10.6-11.2 \mu \mathrm{m})$ of the 11 Landsat 8 bands was used to study temperature differences in water to detect SGD sites. The other Landsat 8 thermal band, 11 TIRS $2(11.50-12.51 \mu \mathrm{m})$, was not used because the data collected in this band have some large calibration uncertainties (U.S. Geological Survey, 2014b).

L174 Please details how cloud and shadow prevent measuring the temperature.

Answer: This information was detailed in the manuscript in the section 3.2.1 (L299). "Clouds and clouds shadows change radiometric information leaving the sea surface and prevent a correct analysis of the images."

Action: No action will be done.

Pg6; L203 what is the name of this tool?

Answer: The name of the tool is Atmospheric Correction Parameter Calculator.

Action: We will specify the name in the new version of the manuscript, now reads (L203 - L205) A web-based atmospheric correction tool (Atmospheric Correction Parameter Calculator) developed by Barsi et al. (2003) based on MODTRAN, was used to obtain values for atmospheric transmissivity and the upwelling and downwelling radiances of the atmosphere.

Pg7; L225 how did you define and calculate the anomaly? 
Answer: Thank you for the comment. We agree with the reviewer about the significance to define and calculate the SGD springs thermal anomaly as we mention in section 3.5 paragraph 573 . However, this preliminary study is not intended to define and calculate the SGD springs thermal anomaly, the aim is to identify the SGD springs. For this reason, we focus on SGD springs previously defined in the scientific literature and we do not monitor some springs during years to understand anomaly changes.

Action: Following the reviewer comment and to be more specific we will modify the text as follows L225- L226):

This qualitative analysis allows us to observe variations in the morphology of the known discharge plume between images.

L237(1) Source?

Answer: Thanks for the comment. The source is Google Earth.

Action: We have corrected the sentence in the revised manuscript, changing "orthophoto maps" from satellite imagery (Google Earth). Now the text reads (L236 L238):

The thermal mapping results were combined with satellite imagery from Google Earth (only the land part) within a GIS to locate the SGD springs at the identified sites.

L237(2) which one?

Answer: Thanks for the comment. The source is QGIS Las Palmas.

Action: Following the reviewer comment we will improve the sentence in the revised manuscript (L237): The thermal mapping results were combined with orthophoto maps (only the land part) within a GIS (QGIS Las Palmas) to locate the SGD springs at the identified sites.

L248 We expect SGD water to be colder and hence higher density. This needs to be elaborated. 
Answer: Groundwater is colder but also less dense than seawater due to its low salinity. For this reason, the inflow of colder groundwater into warmer nearshore waters results in buoyant plumes of low salinity and temperature in the zones of groundwater discharge.

Action: We will modify the text as follows (L247-L249):

.... the thermal contrast in areas of SGD discharge is because the groundwater is located above the seawater because of its lower density due to its different salinity (Wilson \& Rocha, 2012).

Pg11; L404 maximal thermal contrast in winter?

Answer: While the groundwater temperature is relatively constant over time, the temperature of the Mediterranean Sea oscillates seasonally between $18-27^{\circ} \mathrm{C}$ in summer and $14-17^{\circ} \mathrm{C}$ in winter, implying a great contrast between summer and winter.

Action: Following the reviewer comment we will modify the text as follows (L403-L407): The temperature of the Mediterranean Sea oscillates seasonally between $18-27^{\circ} \mathrm{C}$ in summer and $14-17^{\circ} \mathrm{C}$ in winter, while the groundwater temperature relatively constant over time, implying a greater contrast between summer and winter. However, SGD spring visualizations in cloud-free images decrease significantly in winter months compared to warmer months (Figure 4).

\section{L410 I do not understand the last two sentences.}

Answer: As we explained above, summer and winter are the seasons with the highest thermal contrast between submarine groundwater discharge and the sea surface. However, the results showed that the number of the springs identified were higher in summer than in winter (figure 3). This could be related with the fact that during winter months environmental and marine conditions such as wind, currents, etc., could be stronger and make the identification of SGD difficult. These effects are more detailed in the beginning of the section 3.2.3 (Environmental and marine conditions). 
Action: We will rephrase in the reviewed version of the manuscript as follows (L408L411): The number of SGD spring visualizations is much higher in summer than in winter (fig.3). In winter months, wind, water column mixing, currents, etc., are more intense and reduce the thermal contrast. Therefore, environmental and marine conditions during the winter months are unfavorable for the identification of coastal springs.

Pg12; L420 This section is lacking structure. The different factors should be better articulated and discussed in light of your findings. Additionally, the first two paragraphs are theoretical background that are not backed-up with your own results. They should either be moved to the intro or used to discuss the results.

Answer: Thank you for your comment. We have checked this section and we prefer to keep the structure as it is because this small introduction of the factors that may alter the thermal contrast allow a better discussion of the results. Therefore, we prefer to keep it, but we agree to change it if the editor also considers it.

Action: We will articulate better the different factors taking into a count the new box plots figure available in supplementary material.

\section{L432 what is a correct formation?}

Answer: Correct formation means the better depth and distance to the seashore to identify the thermal plume using satellite TIR images.

Action: Following the reviewer comment and in order to clarify the information, the sentence will be rephrased in the reviewed manuscript (L431-L433) as follows:

These two characteristics are very significant, since the location of the SGD spring on the coast is critical for the correct identification of the thermal contrast between groundwater and seawater using satellite thermal images.

Pg13; L462 (1) I do not understand that statement

Answer: Thanks for the comment. 
Action: Following the reviewer comment we will improve the explanation for clarification in the reviewed manuscript and we will move to method section as we explain in the comment below L462 (2).

L462 (2) how did your study show that? Isn't it a description of the study sites instead, hence a statement that should be moved to the method section?

Answer: Thanks for the comment.

Action: Following the reviewer comment we will move and re-elaborate the description of the study sites (flow rates, depth, distance and karst type) to the methods section in the reviewed manuscript (L153 - L183):

The available information for each of the 54 studied springs (Supplementary Material 1) shows that the mean flow rates range between 0.009 and 50 m3Âuss 1 , the distances from the shore range from the coastline to $1 \mathrm{~km}$ offshore, and that discharge depths vary between 7 and $-150 \mathrm{~m}$ with respect to sea level. Attending of these characteristics, we could classify the studied springs in 5 groups. The first group of springs discharge near the seashore and reach the sea through small streams; these karstic springs are located between 300 and $500 \mathrm{~m}$ inland and at elevations of $2 \mathrm{~m}, 3 \mathrm{~m}$ and $15 \mathrm{~m}$ above sea level for Patan in Croatia, Almyros of Iraklio in Greece and Maro in Spain, respectively. The second group of springs discharges in coastal lagoons at a distance of $100 \mathrm{~m}$ from shore and a depth of $-4 \mathrm{~m}$ (Font Dame and Font Estramar in Salses-Laucate lagoon in France) and an unknown shore distance and $-30 \mathrm{~m}$ (Vise in Thau lagoon). The third group of springs is located between 0 and $10 \mathrm{~m}$ from the shoreline and in shallow waters between 0 and $-7 \mathrm{~m}$ (Torre Badum, Las Fuentes, Font de Dins in Spain, Ain Zayana in Libya, Agios Nikolaos, Cephalonia and Anavalos Kiveri in Greece and Ovacik and Gokova in Turkey). The fourth group of springs is located close to the shoreline, but at a water column depth of $-12 \mathrm{~m}$. The two springs of this group are Moraig in Spain and Port Miou and Bestouan in France. The fifth and last group consisting of Mortola in Italy and Chekka in Lebanon, in which discharges oc- 
curs offshore between $100 \mathrm{~m}$ and $1 \mathrm{~km}$ with a water column depth between -35 and $-150 \mathrm{~m}$. The type of coastal karst aquifer has been defined using the same classification as in Tulipano et al. (2005) for Mediterranean coastal karst aquifers. The first type are systems with poorly-developed, but highly fractured karstification. This karst type included 3 different fractured systems in which 1) faults dissect the aquifer such as in the Gokova (4 springs) (Bayari \& Kurttas, 2002) and Ovacik spring, where the faults are located in the underlying beds that extend towards the sea (Elhatip, 2003); 2) groundwater flows along the zones of cracks, fractures and karst hollows, such as in the Donnalucata spring (Povinec et al., 2006); and 3) groundwater flows through stratification joints, such as in the Mortola spring (Fleury et al., 2007). The second type are systems with well-developed karstification connected to the sea (e.g., Moraig, Port Miou, Bestouan, Almyros of Iraklio, Almiros of Agios Nikolaos, Cephalonia, Ain Zayana and Chekka). The last type of defined karst system is one with well-developed karstification but low connectivity with the sea. This group is represented by only two springs: Kiveri Anavalos in Greece and Vise in France.

In addition, we will also restructure the results and discussion section.

Pg 14; L509 Did you test this at all? Did you observe any of these anthropogenic sources? If so, please detail. If not, you can perhaps elaborate on that a bit on your discussion (what are the implications when it comes to using TIRS to detect SGD?), but not present that as a result.

Answer: We have not identified any of these anthropogenic sources in our study that mask or modify our SGD signal. However, we consider this point an important issue to consider since when looking for new springs in remote areas with no complementary information the influence of anthropogenic sources or infrastructures or rivers must be ruled out. As an example, we can clearly observe the water plume discharged by the Vandellós II nuclear power plant in Spain or the thermal water signal of ports (see Figure that we can include in the manuscript if the reviewer considers that will help to understand the importance of this section). 
Action: We will change the name of section 3.2.5 to "Thermal anomalies from streams and anthropogenic sources and rewrite it in the reviewed version of the manuscript as follows:

When looking for coastal thermal anomalies by using satellite TIR images, some anomalies can be detected that are not necessarily due to the SGD. These types of anomalies can be from natural sources, such as small rivers or streams, or civilian facilities such as ports, thermal power plants, fish farms or wastewater treatment plants. These thermal anomalies can misidentify a SGD spring, but can also mask and modify the SGD thermal signal, since despite usually having a different thermal signal due to being highly influenced by atmospheric temperatures, these outflows can modify the thermal signal of the SGD plume. For example, wastewater treatment plant outflows and fish farms could have a similar thermal signal than SGD since they discharge directly to the coastal waters in relatively shallow waters with similar and constant temperature along the year such as SGD springs. In wastewater treatment facilities even when discharged at depth during periods with high stratification, it is possible to detect its thermal effect on the coastal waters (DiGiacomo et al., 2004) with SST differences of at least $0.5{ }^{\circ} \mathrm{C}$ identifiable with TIR-RS (Gierach et al., 2017). In the case of inland aquaculture, pumped seawater temperature may be modified to reach optimal growth conditions and minimize the time to reach commercial size for some species. For instance, water temperature is raised and maintained constant at $21^{\circ} \mathrm{C}$ in European sea bass (Dicentrarchus labrax) hatcheries (Navarro-Martín et al., 2009). The thermal anomaly of civil facilities such as power plants or ports can also be confused with the SGD thermal signal because both affect coastal waters and have relative constant thermal signal along the year. For instance, in the case of the Mediterranean Sea basin we observed during the performance of this study how different facilities along the NE Iberian Peninsula showed thermal anomalies (new figure) such as the nuclear power plant of Vandellós II, Barcelona port, Benicarló port among others. However, none of the karstic springs presented in this study were affected by any river or anthropogenic source. 
L539 what do you mean by "morphological information of the discharge plume"?

Answer: We mean that using multi-temporal SST series, the information of the shape and size of the discharge plume at each time is lost.

Action: Following the reviewer comment we will add the following sentence "morphological information such as shape and size of the discharge plume is lost" in a reviewed manuscript to clarify the message as follows:

Furthermore, with multi-temporal SST series, the temporal morphological information such as shape and size of the discharge plume is lost (Mallast et al., 2013).

Pg15; L549 What criteria allowed to identify that it was indeed a spring?

Answer: All of the SGD springs were described previously in the scientific literature, as it was explained in the introduction section (L130).

"... on the coasts of the Mediterranean Sea basin were used to locate SGD springs described previously in the scientific literature..."

Action: No action will be done.

Pg16; L593 while it is important to be aware of these factors, I do not think it is possible to control or avoid them.

Answer: We agree with the reviewer. However, taking into account the factors discussed in this study, one could, for example, select which period of the year would allow to minimize as much as possible the influence of the different factors involved in the detection of SGD by remote sensing techniques such as the presence of clouds, the maximum thermal contrast between groundwater and sea or the geomorphological characteristics of the coast.

Action: No action will be done.

Fig2 This figure is difficult to read. I suggest to put the dates in larger font. Putting 
negative values in grey for example would also make more sense. I also suggest to try and use the same color scale for all images. Also, the spatial scale is missing.

Answer: We appreciate the suggestion.

Action: Following the reviewer comment in the revised version of the manuscript we will put the dates in larger font and increasing the size of the spatial scale. We will also remove the clouds and use similar temperature ranges (minimum between 10 and $24{ }^{\circ} \mathrm{C}$ and maximum between 21 and $32{ }^{\circ} \mathrm{C}$ ) for all images. We could not use the same color scale for all images as the reviewer suggest because the temperature range changes at each image and if we standardize it, we would not properly see the thermal contrast of all images.

Fig3 (1) are these statistics calculated based on the 1536 or 365 images?

Answer: These statistics were calculated based on springs that we identified at least once using the finer selection of 365 images.

Action: the text will be modified in the revised manuscript for clarification as follows:

Percentage of successful and unsuccessful SGD identifications for all SGD springs that were identified at least once during the 2017-2018 studied period (based on the selection of 365 images).

Fig3 (2) What is in the SM? The percentages is what you show in your figure, so that sentences is confusing.

Answer: In Figure 3 we jointly showed the percentages for the 2017-2018 study period. In supplementary material we showed separately the percentages of the year 2017 in one figure and in another figure the percentages for the year 2018.

Action: We will modify the Figure 3 caption in the revised manuscript for clarification as follows: Percentage of successful and unsuccessful SGD identifications for all SGD springs that were identified at list once throughout the year 2017 and during the year 
2018, are shown individually in the supplementary material.

Fig3 (3) I suggest to repeat that figure by showing the percentage of valid images for which identification was successful versus unsuccessful.

Answer: Thanks for this suggestion. In this figure we showed all the springs that we could identify at least once in the study period to explain in which months we identified the highest success percentage for SGD identification. In that figure, unsuccessful SGD springs identification were not represented because they have not been identified in any month, thus they did not provide additional information about the best season to be able to identify SGD springs.

Action: Following the reviewer comment we will add in the caption of the figure 3 the $\%$ of the springs that are represented in the reviewed version of the manuscript as follows: Percentage of successful and unsuccessful SGD identifications for all SGD springs that were identified at least once (23 springs representing the $44.4 \%$ ) during the studied period 2017-2018.

Fig4 I don't think this can be seen as a conceptual framework. It's rather a list of disconnected factors organized in the form of a diagram. While it certainly has been useful to help organize the writer's thoughts, I do not think it has any interest in this paper. The main problem is that the factors are disconnected and it does not help understanding in what way a given factor influences the identification of SGD.

Answer. We appreciate the comment but we think that these "conceptual framework" is very important. Following the reviewer comment we will change the name of the "conceptual framework in the new version of the manuscript to "Factors for considering in the identification of SGD springs". All these factors will be summarized in this figure.

Action: We will modify this figure to make it more illustrative.

Fig6 It is difficult to see the link between the first and the last three pictures. Could you frame the areas that the pictures $A, B$, and $C$ correspond to in the first picture? 
Also point in the pictures $\mathrm{A}, \mathrm{B}$, and $\mathrm{C}$ what you have identified as the new SDG spring? Lastly, there seem to be a problem with your scales.

Answer: Thank you for the suggestion. We agree that we need to modify the Figure in order to improve the message. We do not understand what you mean with "there seem to be a problem with the scales", since all 3 image scales were checked and were correct.

Action: The figure will be modified in the reviewed version of the manuscript. We could not frame the areas that the pictures $A, B$, and $C$ correspond to in the first picture because spatial scale of the first picture is bigger, and it may not be visible. We will join with an arrow the first and the last three pictures. We will point the SGD identifications in the pictures $A, B$ and $C$.

References used in this letter

Barsi, J. A., Barker, J. L. and Schott, J. R.: An Atmospheric Correction Parameter Calculator for a Single Thermal Band Earth-Sensing Instrument, Int. Geosci. Remote Sens. Symp., 5(C), 3014-3016, doi:10.1109/igarss.2003.1294665, 2003.

Bejannin, S., van Beek, P., Stieglitz, T., Souhaut, M. and Tamborski, J.: Combining airborne thermal infrared images and radium isotopes to study submarine groundwater discharge along the French Mediterranean coastline, J. Hydrol. Reg. Stud., 13(February), 72-90, doi:10.1016/j.ejrh.2017.08.001, 2017.

Bakalowicz, M.: Coastal Karst groundwater in the mediterranean: A resource to be preferably exploited onshore, not from Karst Submarine springs, Geosci., 8(7), doi:10.3390/geosciences8070258, 2018.

Basterretxea, G., Tovar-Sanchez, A., Beck, A. J., Masqué, P., Bokuniewicz, H. J., Coffey, R., Duarte, C. M., Garcia-Orellana, J., Garcia-Solsona, E., Martinez-Ribes, L. and Vaquer-Sunyer, R.: Submarine groundwater discharge to the coastal environment of a Mediterranean island (Majorca, Spain): Ecosystem and biogeochemical significance, 
Ecosystems, 13(5), 629-643, doi:10.1007/s10021-010-9334-5, 2010.

Bayari, C. S. and Kurttaş, T.: Coastal and submarine karstic discharges in the Gökova

Bay, SW Turkey, Q. J. Eng. Geol. Hydrogeol., 35(4), 381-390, doi:10.1144/14709236/01034, 2002.

Chander, G., Markham, B. L. and Helder, D. L.: Summary of current radiometric calibration coefficients for Landsat MSS, TM, ETM+, and EO-1 ALI sensors, Remote Sens. Environ., 113(5), 893-903, doi:10.1016/j.rse.2009.01.007, 2009.

DiGiacomo, P. M., Washburn, L., Holt, B. and Jones, B. H.: Coastal pollution hazards in southern California observed by SAR imagery: Stormwater plumes, wastewater plumes, and natural hydrocarbon seeps, Mar. Pollut. Bull., 49(11-12), 1013-1024, doi:10.1016/j.marpolbul.2004.07.016, 2004.

Elhatip, $\mathrm{H}$.: The use of hydrochemical techniques to estimate the discharge of Ovac1k submarine springs on the Mediterranean coast of Turkey, Environ. Geol., 43(6), 714719, doi:10.1007/s00254-002-0668-y, 2003.

Fleury, P., Bakalowicz, M. and de Marsily, G.: Submarine springs and coastal karst aquifers: A review, J. Hydrol., 339(1-2), 79-92, doi:10.1016/j.jhydrol.2007.03.009, 2007.

Garcia-Solsona, E., Garcia-Orellana, J., Masqué, P., Garcés, E., Radakovitch, O., Mayer, A., Estradé, S. and Basterretxea, G.: An assessment of karstic submarine groundwater and associated nutrient discharge to a Mediterranean coastal area (Balearic Islands, Spain) using radium isotopes, Biogeochemistry, 97(2), 211-229, doi:10.1007/s10533-009-9368-y, 2010.

Gierach, M. M., Holt, B., Trinh, R., Jack Pan, B. and Rains, C.: Satellite detection of wastewater diversion plumes in Southern California, Estuar. Coast. Shelf Sci., 186, 171-182, doi:10.1016/j.ecss.2016.10.012, 2017.

Johnson, A. G., Glenn, C. R., Burnett, W. C., Peterson, R. N. and Lucey, P. G.: Aerial 
infrared imaging reveals large nutrient-rich groundwater inputs to the ocean, Geophys. Res. Lett., 35(15), 1-6, doi:10.1029/2008GL034574, 2008.

Mallast, U., Gloaguen, R., Friesen, J., Rödiger, T., Geyer, S., Merz, R. and Siebert, C.: How to identify groundwater-caused thermal anomalies in lakes based on multitemporal satellite data in semi-arid regions, Hydrol. Earth Syst. Sci., 18(7), 2773-2787, doi:10.5194/hess-18-2773-2014, 2014.

Mejías, M., Ballesteros, B. J., Antón-Pacheco, C., Domínguez, J. A., Garcia-Orellana, J., Garcia-Solsona, E. and Masqué, P.: Methodological study of submarine groundwater discharge from a karstic aquifer in the Western Mediterranean Sea, J. Hydrol., 464-465, 27-40, doi:10.1016/j.jhydrol.2012.06.020, 2012.

Moosdorf, N. and Oehler, T.: Societal use of fresh submarine groundwater discharge: An overlooked water resource, Earth-Science Rev., 171(August 2016), 338348, doi:10.1016/j.earscirev.2017.06.006, 2017.

Navarro-Martín, L., Blázquez, M., Viñas, J., Joly, S. and Piferrer, F.: Balancing the effects of rearing at low temperature during early development on sex ratios, growth and maturation in the European sea bass (Dicentrarchus labrax). Limitations and opportunities for the production of highly female-biased stocks, Aquaculture, 296(3-4), 347-358, doi:10.1016/j.aquaculture.2009.07.022, 2009.

Oehler, T., Eiche, E., Putra, D., Adyasari, D., Hennig, H., Mallast, U. and Moosdorf, N.: Seasonal variability of land-ocean groundwater nutrient fluxes from a tropical karstic region (southern Java, Indonesia), J. Hydrol., 565(July), 662-671, doi:10.1016/j.jhydrol.2018.08.077, 2018.

Povinec, P. P., Aggarwal, P. K., Aureli, A., Burnett, W. C., Kontar, E. A., Kulkarni, K. M., Moore, W. S., Rajar, R., Taniguchi, M., Comanducci, J. F., Cusimano, G., Dulaiova, H., Gatto, L., Groening, M., Hauser, S., Levy-Palomo, I., Oregioni, B., Ozorovich, Y. R., Privitera, A. M. G. and Schiavo, M. A.: Characterisation of submarine ground- 
water discharge offshore south-eastern Sicily, J. Environ. Radioact., 89(1), 81-101, doi:10.1016/j.jenvrad.2006.03.008, 2006.

Rodellas, V., Garcia-Orellana, J., Masqué, P., Feldman, M., Weinstein, Y. and Boyle, E. A.: Submarine groundwater discharge as a major source of nutrients to the Mediterranean Sea, Proc. Natl. Acad. Sci. U. S. A., 112(13), 3926-3930, doi:10.1073/pnas.1419049112, 2015.

Tulipano, L., Panagopoulus, A. and Fidelibus, M. D.: COST ACTION 621"Groundwater management of coastal karstic aquifers",Final Report., 2005.

Wen-Yao, L., Field, R. T., Gantt, R. G. and Klemas, V.: Measurement of the Surface Emissivity, Remote Sens. Environ., 5(4), 97-109, doi:10.1016/0034-4257(87)90009-5, 1987.

Wilson, J. and Rocha, C.: Regional scale assessment of Submarine Groundwater Discharge in Ireland combining medium resolution satellite imagery and geochemical tracing techniques, Remote Sens. Environ., 119, 21-34, doi:10.1016/j.rse.2011.11.018, 2012.

Interactive comment on Hydrol. Earth Syst. Sci. Discuss., https://doi.org/10.5194/hess-2020569, 2020. 


\section{HESSD}

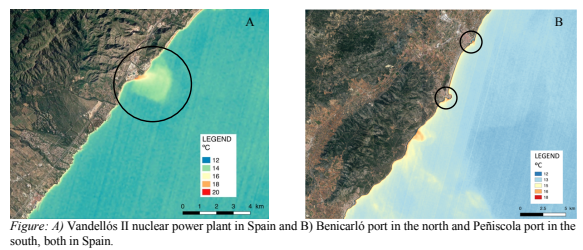

Interactive

comment

Fig. 1. 


\section{HESSD}

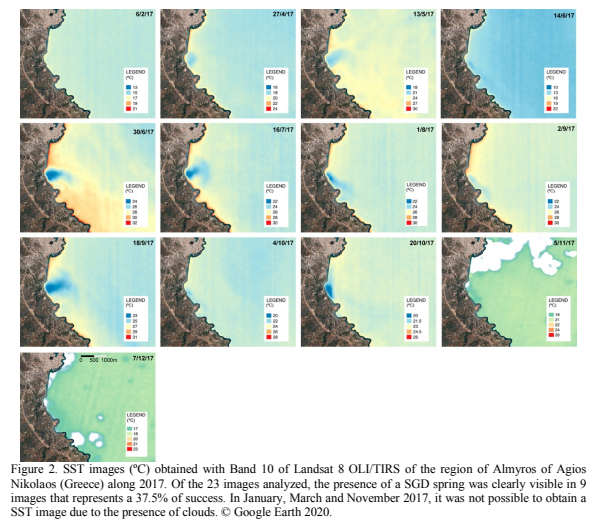

Interactive comment

Fig. 2. 


\section{HESSD}

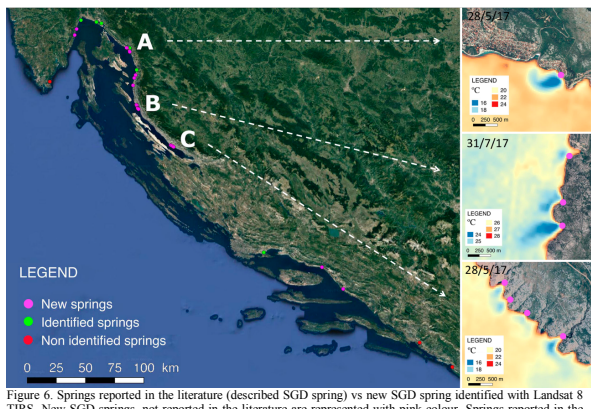

Interactive

comment

Fig. 3. 